\title{
Pesquisa em educação ambiental e percepção ambiental
}

\author{
Andreia Aparecida Marin ${ }^{1}$ \\ UFPR - Departamento de Teoria e Prática de Ensino
}

resumo: Este texto tem como objetivo fornecer uma breve composição histórica do campo de pesquisas em percepção ambiental, especialmente sobre como as reflexões ali geradas têm sido incorporadas nas pesquisas em educação ambiental. Para tanto, parte-se da demarcação da origem dos estudos sobre percepção na Psicologia e do momento em que eles deixam essa base no tratamento dos temas relacionados para entrar em outras áreas do conhecimento, como a arquitetura e a geografia humana, nas quais receberão a influência de outras abordagens, como a fenomenologia. É feita, na seqüência, a menção a algumas produções em percepção ambiental no país. São tratadas ainda as atuais influências da filosofia, especialmente da teoria estética, nas pesquisas com percepção. A síntese do texto é formulada com base nas discussões desenvolvidas nos trabalhos do Grupo de Discussões em Percepção Ambiental do IV Encontro de Pesquisa em Educação Ambiental (EPEA), nos quais se pontuaram as principais demandas e perspectivas dos estudos no campo.

palavras-chave: Percepção Ambiental, Educação Ambiental, Pesquisa.

abstract: This article aims to provide a brief historical overview of the research field of environmental perception, focusing on how the reflections produced by it have been incorporated in environmental education research. In order to do so, we first analyse the origins of the perception studies in psychology and the moment when they leave that base so as to enter other knowledge fields, such as architecture and human geography, where they will be influenced by different approaches, including phenomenology. After that, we mention some Brazilian works on environmental perception. We also refer to current philosophical influences on perception research, especially from the aesthetic theory. Finally, we sum up these ideas based on the discussions by the Discussion Group on Environmental Perception at the IV Research Meeting on Environmental Education (EPEA), where the researchers involved pointed out the main requirements and perspectives of the studies in this field.

keywords: Environmental Perception, Environmental Education, Research.

${ }^{1}$ Contato: aamarin@ufpr.br 


\section{Introdução}

Estudos sobre percepção ambiental no campo da educação ambiental são iniciativas que podemos considerar relativamente novas, se comparadas à inserção da temática em outros campos de conhecimento, como a psicologia e a geografia. Há, no entanto, uma preocupação recente que diz respeito às formas como essas iniciativas têm sido conduzidas, principalmente quanto à adoção dos referenciais teóricos e às diferentes questões e abordagens de pesquisa que são ancoradas no tema, algumas vezes desprovidas do entendimento do seu real significado.

Essa aparente fragilidade nos estudos da percepção não representa, no entanto, um fator isolado dentro do campo, uma vez que outros fenômenos e seus respectivos arcabouços teóricos, como as representações sociais, são muitas vezes adotados sem que haja uma clareza na apresentação dos referenciais teórico-metodológicos e na justificativa de focalização das temáticas e problemas de pesquisas nessas abordagens. Esse é o caso, por exemplo, de vários estudos em que se propõe a compreensão das percepções e representações e que resultam em levantamentos conceituais que, apesar de estabelecerem categorizações interessantes e importantes para o entendimento da linguagem e do discurso corrente sobre as questões ambientais, não dão conta de subsidiar uma discussão mais aprofundada sobre o que deveriam ser suas preocupações centrais, a saber: a natureza e as formas de relação do ser humano com as realidades imediatas, onde se inserem a coletividade e o lugar habitado, nos estudos de percepção; as formas com que essa relação é influenciada por conhecimentos e discursos construídos socialmente, importando também o entendimento dos processos históricos e culturais dessa construção, nas investigações sobre representação social.

Retomemos, para melhor fundamentar essas inquietações, algumas reflexões desenvolvidas em outros momentos no histórico de nossos encontros. Em considerações sobre as tendências dos trabalhos de pesquisa em Educação Ambiental, Freitas e Oliveira (2006, p. 185) apontam as "fragilidades na abordagem de temas situados nas fronteiras" das ciências humanas, agravadas também pelo fato de os pesquisadores do campo virem 
das ciências naturais: "Muitos dos relatos trazem como quadro teórico um painel de opiniões de diferentes autoras e autores sobre o que seja a crise ambiental e seus desdobramentos" (FREITAS; OLIVEIRA, 2006, p. 185, grifo do autor). As autoras afirmam algo que vai perfeitamente ao encontro de nossas preocupações aqui:

[...] o arcabouço formado por elementos tomados como categorias que permitam compreender um determinado fenômeno da realidade, ou seja, os fios condutores para a pesquisa e a ação educativa, na grande maioria dos relatos analisados, não são intencionalmente apresentados (FREITAS; OLIVEIRA, 2006, p. 186, grifo nosso).

Em um levantamento analítico a respeito dos referenciais teóricos adotados nas pesquisas veiculadas nos últimos cinco anos em alguns eventos do campo (EPEA e Ibero-americano de EA) e algumas revistas nacionais, Daniel (2006) também evidencia a pobreza teórico-metodológica dos trabalhos. Contudo, essa é uma situação que comungamos com o histórico de consolidação do campo da educação. A falta de respaldo teórico é apontada por André (2001, p. 61) como o principal problema das pesquisas em educação. Alves-Mazzotti (2001, p. 40) também coloca a pobreza teórico-metodológica na abordagem dos temas como a principal crítica ao campo, além de enfatizar que há uma adoção acrítica de modismos na seleção de quadros teórico-metodológicos.

Com essas preocupações definidas, partimos aqui para a construção de reflexões sobre a inserção da temática da Percepção Ambiental nas pesquisas no campo da educação ambiental. Para tanto, é conveniente buscarmos o entendimento de como as pesquisas sobre percepção se desenvolveram em seu campo de origem - a psicologia - e, mais recentemente, nas diferentes áreas do conhecimento, entre as quais destacamos: a própria psicologia, com a formação do campo da psicologia ambiental; a arquitetura e urbanismo, principalmente com a adoção dos referenciais da psicologia; a geografia, mais precisamente, a geografia humana; a filosofia, com o aporte dos princípios fenomenológicos, que inclusive influenciaram direta ou indiretamente as demais áreas. 


\section{Os estudos de percepção}

O termo percepção, derivado do latim perception, é definido na maioria dos dicionários da língua portuguesa como: ato ou efeito de perceber; combinação dos sentidos no reconhecimento de um objeto; recepção de um estímulo; faculdade de conhecer independentemente dos sentidos; sensação; intuição; idéia; imagem; representação intelectual. Não é difícil identificar uma amplitude considerável de possíveis significados a partir dessas definições, que vão desde a recepção de estímulos até a intuição, a idéia e a imagem, que são categorias perfeitamente distintas no discurso filosófico. Essa complexidade do termo reflete uma nebulosidade também no entendimento do fenômeno, responsável por uma insistência permanente na busca por elucidações em toda a história do pensamento humano, cuja expressão primeira é a existência de distintas teorias, como os idealismos, os empirismos, o realismo e o materialismo. O plural das duas primeiras denominações é proposital, uma vez que há diferentes formas de elaboração dessas visões.

$\mathrm{Na}$ própria definição, também podemos destacar uma característica que já nos fala um pouco do histórico das pesquisas sobre o fenômeno: uso dos sentidos no reconhecimento de um objeto e resposta a estímulos revelam a base conceitual desenvolvida originalmente nos campos da psicologia, mais enfaticamente, da psicologia comportamentalista, que inclusive abrigou por um longo tempo os interesses de pesquisa.

De acordo com o psicólogo Hochberg (1973, p. 11), “a percepção é um dos mais antigos temas de especulação e pesquisa no estudo do homem [...] Estudamos a percepção numa tentativa de explicar nossas observações do mundo que nos rodeia”. Ele enfatiza que o estudo da percepção começou muito antes de existir a ciência da Psicologia, sendo as primeiras pesquisas obra de fisiologistas e físicos. Notamos, portanto, que o enfoque dos estudos, a essa época, estava voltado para o entendimento dos mecanismos físicos, que definiam o mundo, e biológicos do fenômeno, sendo que se justificavam pela necessidade de correção dos dados da percepção com o rigor da ciência, que, segundo o autor, "dá conta de explicar completamente o mundo e o que nele existe” (HOCHBERG, 1973, p. 12). 
Em 1879, Wilhelm Wundt (1832-1920), usualmente citado como o pai da psicologia científica, fundou, em Leipzig, o primeiro laboratório de psicologia experimental, no qual estudou principalmente a percepção humana. O foco desses estudos estava, como o próprio autor apresenta, nos estímulos externos e internos responsáveis pelos comportamentos dos organismos (SIMÕES; TIEDEMANN, 1985, p. ix).

Esse enfoque biofísico e comportamentalista, centrado na visão mecanicista da ciência moderna, influenciou também as vertentes da psicologia que passaram a estudar a percepção. Primeiramente, as mais tradicionais, como: o introspeccionismo (mentalismo) e o estruturalismo, segundo Lee (1977, p. 32), preocupadas em descobrir "moléculas irredutíveis" da cognição; o behaviorismo, cujo foco são comportamentos diretamente observáveis como respostas a estímulos ambientais, e a própria psicologia ambiental, que, principalmente na sua fase inicial, adotou o princípio dessas abordagens. O início da superação desse enfoque se dá sobretudo com a reflexão e adoção dos princípios da Gestalt (1920-1930), ou Psicologia da forma, pela psicologia ambiental e outras áreas de conhecimento. Vale antecipar o destaque ao fato de essa teoria ter estreita relação com os fundamentos da fenomenologia, que influenciou uma nova vertente dos estudos sobre percepção. Essas vertentes clássicas da psicologia foram duramente criticadas por Merleau-Ponty, uma vez que renunciavam o mundo vivido, em favor daquele que a inteligência construía (CARMO, 2000, p. 50).

O estabelecimento do campo da psicologia ambiental iria consolidar o interesse dos estudos em percepção a partir da década de sessenta, sendo o período anterior caracterizado por investigações dispersas sobre as relações do ser humano com seu ambiente (LEE, 1977, p. 12). Com a configuração do campo, houve uma tendência de superação das abordagens tradicionais:

A psicologia ambiental é distinguível dos campos tradicionais da percepção porque a maioria dos estímulos de que esta última se ocupa, embora provenientes do meio físico, foram deles extraídos e aplicados a indivíduos cativos na situação controlada de laboratório [...] Isso constitui um procedimento muito adequado aos cientistas, e 
muito nos ensinou acerca das características dos estímulos e dos vários modos como as pessoas lhes respondem, mas diz-nos muito pouco sobre o meio ambiente (LEE, 1977, p. 13).

Essa crítica, no entanto, não significou uma mudança imediata nos enfoques dos estudos sobre percepção ambiental, uma vez que havia uma multiplicidade de abordagens possíveis, incluindo-se alguns estudos ancorados na psicanálise, que, apesar de um uso restrito, segundo Lee (1977, p. 31), se destacaram na estruturação do campo. Heimstra e MacFarling (1978), na obra Psicologia ambiental, afirmam que até aquele momento simplesmente não havia no campo teoria própria e a maioria das questões investigadas dizia respeito ao comportamento humano em relação ao ambiente físico. $\mathrm{Na}$ obra, destacam a variação de comportamento em ambientes construídos (salas, moradias, edifícios, cidades), inclusive já discutindo mapas psicológicos, condições de estresse e de satisfação residencial, e naturais (recreação, parques e percepção de perigos naturais).

A influência da Gestalt na Psicologia ambiental foi significativa a partir de um dado momento. Durante o século XIX e até o início do século $\mathrm{XX}$, os estudos sobre a percepção humana da forma tinham em comum a análise atomista, segundo a qual a percepção de um objeto era dada pelas suas partes componentes, organizadas posteriormente por associação. A Teoria da Gestalt, surgida no início do século XX, se volta contra isso e afirma que não se pode ter conhecimento do todo através das partes, e sim das partes através do todo e que só através da percepção da totalidade é que a razão pode decodificar e assimilar uma imagem ou um conceito. Tendo seu início com as idéias de psicólogos alemães e austríacos, como Max Wertheimer, Christian von Ehrenfels, Felix Krüger, Wolfgang Köhler e Kurt Koffka, se configura também como campo filosófico, principalmente a partir dos estudos de percepção das cores de Goethe e, posteriormente, pela influência na fenomenologia e no existencialismo.

É nessa nova fase de consolidação teórica que os estudos de percepção ambiental se alastram por outras áreas de conhecimento. Não obstante, os trabalhos iniciais nessas áreas mantiveram um forte enfoque psicologista, buscando somente mais recentemente as bases teóricas na 
filosofia, através do viés fenomenológico. Del Rio e Oliveira (1999, p. x) afirmam que "disciplinas como a arquitetura, o urbanismo e a geografia souberam compreender rapidamente a importância da psicologia aplicada ao espaço" e destacam que nossas preocupações poderiam ser situadas no escopo da cognição. A própria fenomenologia tem sido, no entanto, base teórica presente nos estudos dessas diferentes áreas.

\section{Os estudos de percepção ambiental na geografia e na arquitetura}

Em levantamento dos grupos de pesquisa sobre Percepção Ambiental existentes no período de 1997 a 2001, Pinheiro (2005, p. 106) destaca que $64 \%$ dos grupos se auto-identificam como da área de Psicologia, $18 \%$, da Arquitetura e Urbanismo e o restante, de outras áreas, como Educação, Sociologia, Engenharia e Recursos Florestais. O autor aponta o caráter incipiente da Psicologia Ambiental no país até a segunda metade da década de noventa (PINHEIRO, 2005, p. 105).

Em nível internacional, o início da década de setenta pode ser considerado o momento da disseminação das pesquisas sobre a temática, especialmente derivado da constituição do grupo Man and Biosphere - 13 (MAB) na UNESCO, cujo foco das questões era a Percepção do Meio Ambiente. De acordo com Melo (2005, p. 9150), o projeto da UNESCO enfatizava o estudo da percepção do meio ambiente como fundamental para a gestão de lugares e paisagens que tinham importância para a humanidade, e o objetivo do MAB era estudar as relações entre as populações e o meio ambiente em diversas cidades em torno do mundo, distribuídas em um conjunto de 40 países, entre elas a cidade de Porto Alegre.

Um marco importante do desenvolvimento do campo foi a sugestão do termo Humanistic Geography por Tuan no encontro da Association of American Geographers, em 1976, cujo pensamento foi consolidado na publicação da obra Topofilia (1980), utilizando-se de um termo e conceito originalmente apresentados por Bachelard, na primeira edição de sua obra $A$ Poética do Espaço (1951). Na apresentação do termo "humanístico", Tuan (1976, p. 1) coloca que a Geografia Humanística não é uma ciência da terra em seu objetivo final, mas se entrosa com as Humanidades e Ciências 
Sociais porque todas compartilham a esperança de prover uma visão precisa do mundo humano:

A Geografia Humanística procura um entendimento do mundo humano através do estudo; das relações das pessoas com a natureza, do seu comportamento geográfico bem como dos seus sentimentos e idéias a respeito do espaço e do lugar.

Outra referência de grande importância no histórico do campo, segundo a pesquisadora Lívia de Oliveira (2001, p. 15), foi a publicação da obra da geógrafa Anne White, em 1977 - Guidelines for fields studies in environmental perception, que representou referência fundamental nos primeiros estudos desenvolvidos no Brasil, nas décadas de setenta e oitenta. Esses estudos foram motivados, em grande parte, pelos trabalhos da referida pesquisadora - Lívia de Oliveira -, que inseria no espaço nacional as reflexões desenvolvidas na década de setenta, nas conferências sobre o tema e nas obras publicadas por autores como Ian Burton, diretor do grupo MAB, David Lowenthal, Anne Buttimer, Kevin Lynch e Edward Relph. Este último havia proposto, já em 1971, a terminologia Geografia Fenomenológica ao campo, dado o enfoque de suas reflexões em MerleauPonty e Bachelard, o que pode ser encontrado na sua obra Place and Placelessness, de 1976.

É importante salientarmos ainda dois apontamentos feitos por Oliveira (2001, p. 18-19), com relação às categorias espaço, lugar e paisagem, que, no decorrer da década de setenta, passam a ter uma abordagem centrada na dimensão humana: o conceito de paisagem não se restringiria ao âmbito da natureza, mas envolveria o ser humano com consciência, afetividade e conhecimento crítico; espaço seria definido como espaço vivido e lugares, como dimensão existencial e perceptiva. Essas categorias redefinidas seriam o cerne de uma geografia não positivista, que havia então se denominado Geografia Humanística.

Em nível nacional, a Geografia apresentaria a primeira dissertação sobre o tema, em 1982, de Lineu Bley/UFPR, seguida de vários trabalhos desenvolvidos na UNESP/Rio Claro e, posteriormente, em outras 
instituições de pesquisa (maiores detalhes, ver OLIVEIRA, 2001; DEL RIO; OLIVEIRA, 1999).

$\mathrm{Na}$ Arquitetura e Urbanismo, o principal ponto de reflexão para a origem da inquietação com a percepção ambiental é, de acordo com o arquiteto Okamoto (2002, p. 9), a necessidade de "criar o ambiente perceptivo do homem para seu desenvolvimento adequado, utilizando uma linguagem ambiental". Parte, portanto, da importância que deve ser dada às aspirações humanas, não atendidas pela racionalidade estrita da cultura ocidental, como emoção e afetividade em relação ao meio ambiente, que dão o sentido dos lugares vivenciados. A constituição do espaço arquitetônico deve favorecer o "equilíbrio, a harmonia e a evolução espiritual do homem, atendendo às suas aspirações, acalentando seus sonhos, instigando as emoções de se sentir vivo, desenvolvendo nele um sentido afetivo em relação ao locus" (OKAMOTO, 2002, p. 15).

Logicamente, existiram em algumas iniciativas ao longo do histórico das pesquisas na área os interesses mais imediatos, centrados no caráter comportamentalista e funcional, mas essa abordagem humanística sem dúvida ganhou espaço nas últimas décadas, ao menos no espaço das pesquisas. Fatores condicionantes da percepção como educação, crenças pessoais, cosmovisões e valores pessoais, culturais e sociais são considerados nas pesquisas na área (OKAMOTO, 2002, p. 10).

A arquitetura teria, nesse sentido, o papel de reverter um quadro importante nas sociedades contemporâneas, marcado pela supervalorização das imagens hiper-reais globalizantes, em detrimentos das imagens concretas dos lugares habitados. Esse tema é desenvolvido por Otília Arantes, na obra O lugar da arquitetura depois dos modernos, de 1993. É um tema também recentemente trabalhado no campo da Educação e da Educação Ambiental, como destacaremos posteriormente.

Fróis (2001, p. 124) aponta a transição que ocorre no campo da arquitetura na modernidade: "Ao homem moderno não cabe mais o olhar contemplativo ingênuo, destituído da necessária comunhão com o objeto de análise, nem a catalogação sistemática, destituída da experienciação daquele". Para a autora, o objeto arquitetônico não mais será abordado como objeto isolado em si, mas como fenômeno que se apresenta inserido no mundo. Essa 
nova abordagem da arquitetura pode ser bem compreendida a partir das obras de Norberg-Schulz, que desenvolveu a fundamentação fenomenológica da geografia. De acordo com Norberg-Schulz (1975 apud FRÓIS, 2001, p. 127), nossa consciência de espaço está baseada nas experiências com coisas e os esquemas de percepção do espaço são "determinados culturalmente e compreendem propriedades qualitativas, resultantes da necessidade de uma orientação afetiva em relação a seu entorno".

Em obra intitulada Percep̧cão ambiental: a experiência brasileira, de 1999, o arquiteto Vicente Del Rio e a geógrafa Lívia de Oliveira apresentam uma coletânea dos trabalhos desenvolvidos no país, situando-os em duas abordagens teóricas principais: estruturalismo e fenomenologia. Essa classificação deve ser vista com cautela, uma vez que o estruturalismo, que entende "a realidade como um conjunto de sistemas cujas estruturas são reconhecíveis e onde qualquer alteração por uma parte tenderá a se refletir no todo", tem sido alvo de críticas de pesquisadores das ciências humanas que nele enxergam ranços do paradigma positivista revestido de uma linguagem sociológica. A fenomenologia, por sua vez, tem influenciado diretamente vários estudos no campo, embora muitas vezes não seja apresentada com referências claras.

Importa, para nossas discussões, uma classificação dos estudos, que os autores fazem no prefácio da obra, a partir da qual podemos começar a elucidar as vertentes teóricas do campo: estudos de caráter intervencionista, preocupados com o entendimento da percepção para projetos de gestão ambiental; estudos de caráter interpretativo, envolvendo investigações fenomenológicas e de construção social do universo simbólico; estudos de caráter educacional, nos quais a percepção é parte do processo de formação de conhecimentos e, conseqüentemente, de valores. Podemos ver no Quadro 1, apresentado a seguir, os estudos e referenciais agrupados nessas categorias. 


\begin{tabular}{|c|c|c|}
\hline Categorias* & Foco do estudo & Referenciais \\
\hline \multirow[t]{2}{*}{ Intervencionista } & $\begin{array}{l}\text { Estudos da arquitetura e } \\
\text { urbanismo para projetos de } \\
\text { gestão ambiental }\end{array}$ & $\begin{array}{l}\text { Kevin Lynch } \\
\text { Gordon Cullen }\end{array}$ \\
\hline & Percepção visual da cidade & Gestalt \\
\hline \multirow[t]{3}{*}{ Interpretativa } & $\begin{array}{l}\text { Percepção como fenômeno de } \\
\text { comunicação }\end{array}$ & $\begin{array}{l}\text { Semiótica } \\
\text { Charles Peirce, Saussure, } \\
\text { Barthes e Umberto Eco }\end{array}$ \\
\hline & $\begin{array}{l}\text { Construção social da imagem, } \\
\text { comportamento social, uso de } \\
\text { espaços simbólicos e mitos da } \\
\text { vida urbana } \\
\end{array}$ & $\begin{array}{l}\text { Construtivismo social } \\
\text { Sociologia/comunicação } \\
\text { social }\end{array}$ \\
\hline & $\begin{array}{l}\text { Compreensão fenomenológica } \\
\text { do meio ambiente } \\
\text { (significados das dimensões } \\
\text { física, social, psicológica e } \\
\text { imaginária) } \\
\text { *incluindo estudos da } \\
\text { percepção na literatura }\end{array}$ & $\begin{array}{l}\text { Geografia humanística } \\
\text { Tuan } \\
\text { Christian Norberg-Schulz } \\
\text { (Fenomenologia da } \\
\text { Arquitetura) } \\
\text { Roland Barthes, Antoine } \\
\text { Bailly }\end{array}$ \\
\hline Educacionais & $\begin{array}{l}\text { Formação de conhecimento, } \\
\text { sistema de valores; ensino de } \\
\text { classes populares; percepção } \\
\text { de riscos ambientais }\end{array}$ & $\begin{array}{l}\text { Educação, educação } \\
\text { ambiental, áreas específicas } \\
\text { relacionadas aos temas }\end{array}$ \\
\hline
\end{tabular}

Quadro 1. Natureza dos trabalhos publicados na obra Percepção ambiental: a experiência brasileira. (*A denominação das categorias foi criada por nós com base nas descrições e detalhamentos dos autores, para facilitar a compreensão)

Vale ressaltar que os autores dessas pesquisas são pesquisadores das áreas: arquitetura (UFRJ, UnB, USP); geografia (USP, UNESP), literatura (UFPE). Os autores destacam ainda outras temáticas em desenvolvimento: percepção e comportamento em conjuntos habitacionais (UFRGS); percepção e direito ambiental (UNESP); percepção e vandalismo em escolas 
públicas (UFPE); percepção e imagens populares de paisagens (UNESP); percepção visual na arquitetura (FAUUSP); produção da imagem social da cidade (UFRJ). Em obra posterior, Del Rio et al. (2002) apontam dois pólos importantes de produção no campo que reúnem oito grupos de pesquisa: PROARQ e Instituto de Psicologia, na UFRJ, e REPALA (Rede de Psicologia Ambiental da América Latina), na UFRN (para maiores detalhes sobre as pesquisas desenvolvidas em âmbito nacional, consultar DEL RIO; OLIVEIRA, 1999 e DEL RIO et al., 2002).

Uma consideração importante com relação aos referenciais diz respeito ao fato de os trabalhos que adotam a fenomenologia não fazerem referência direta às suas bases. De acordo com Pacheco e Silva (2005, p. 3), a vertente fenomenológica tem em Tuan e na geografia humanística a sua inspiração mais forte.

\section{Os aportes filosóficos nas pesquisas}

Algumas pesquisas mais recentes sobre percepção ambiental no campo da educação ambiental, da sociologia e da geografia têm apresentado importantes aportes teóricos advindos da área filosófica. Fazem parte dessas pesquisas: os estudos teóricos sobre leituras da percepção ambiental a partir da Fenomenologia da Percepção, de Merleau-Ponty (1999); estudos sobre as dimensões fluidas do humano - imaginação e afetividade, na sua relação com o ambiente, inspirados nas obras da fase noturna do filósofo Bachelard, principalmente em A Poética do Espaço (1993); estudos das dimensões simbólicas da relação ser humano-ambiente, a partir dos pensamentos de Ernest Cassirer e Mircea Eliade, nas suas respectivas obras $A$ filosofia das formas simbólicas (2001) e Imagens e símbolos (1991); suas derivações em estudos sobre as constituições imaginárias da relação sociedade-natureza, cuja principal contribuição são as discussões filosóficas desenvolvidas pelo sociólogo Maffesoli, especialmente em sua obra No fundo das aparências (1996); e, mais recentemente, estudos que tratam das aproximações epistemológicas entre a Teoria Estética e a percepção ambiental, fundamentados principalmente nos filósofos Mikel Dufrenne, autor de Estética e filosofia (2002), Alfonso López Quintás, em Estética (1992), e 
também Bachelard. Na análise dos espaços vividos, segundo Serpa (2001, p. 34), a fenomenologia da imaginação de Bachelard exige que "vivamos diretamente as imagens, que as consideremos como acontecimentos súbitos da vida”. As discussões da estética permitem uma importante reflexão para a educação ambiental no que diz respeito às perdas de contato com a concretude nos grandes centros urbanos, que significam também perda de contato com a natureza e o lugar habitado, em função da disseminação das hiper-realidades e proliferação dos não-lugares, que dessensibilizam cada vez mais o ser humano. Essa reflexão pode receber importante contribuição das obras de João Francisco Duarte: Fundamentos estéticos da educação (1988) e O sentido dos sentidos (2004).

A fenomenologia de Edmund Husserl (1859-1938) tem por objetivo a descrição pura da realidade, o retorno ou resgate do fenômeno em si. Surge no início do século XX, num contexto de crise dos paradigmas das ciências e dos pensamentos filosóficos. Contra a dedução, tantas vezes reducionista das coisas, a fenomenologia exercita a descrição destas por meio da redução eidética. A partir de um discurso minucioso e esclarecedor, pode-se esclarecer aquilo que se mostra a si mesmo. Para se chegar a ele, é preciso, portanto, que se viva a liberdade dos preconceitos e a suspensão provisória de nossas reflexões e lógicas para mergulharmos no que se revela na percepção, na essência das coisas - a redução fenomenológica ou epoché. Segundo Holzer (1996, p. 12), a inserção da fenomenologia nos estudos de percepção ambiental é utilizada na intenção de se fazer uma descrição rigorosa do mundo vivido da experiência humana. $\mathrm{O}$ espaço vivido é uma categoria fundamental nos estudos de geografia humana.

O existencialismo de Sartre (1905-1980) e a Hermenêutica de Heidegger (1889-1976) influenciam a filosofia fenomenológica do filósofo francês Merleau-Ponty (1907-1961). Os pontos principais de seu pensamento são: existência do mundo independentemente das considerações que se possam fazer dele; inseparabilidade entre sujeito e seu mundo e construção recíproca entre eles; o corpo como conexão do sujeito ao seu mundo; percepção do espaço como expressão da vida total do sujeito; consciência e mundo ligados pela percepção (não há consciência do mundo possível após desligamento); consciência ativa/analítica 
(entendimento) e passiva (percepção) (MARIN, 2003; MARIN et al., 2003; FRÓIS, 2001; CARMO, 2000).

Tudo aquilo que sei do mundo, mesmo por ciência, eu o sei a partir de uma visão minha ou de uma experiência do mundo sem a qual os símbolos da ciência não poderiam dizer nada [...] Retornar às coisas mesmas é retornar a este mundo anterior ao conhecimento do qual o conhecimento sempre fala. (MERLEAU-PONTY, 1999, p. 3).

\section{Contra quais fenômenos o entendimento da percepção ambiental se apresenta}

Podemos, a partir dessa breve contextualização, abrir alguns questionamentos importantes com relação às pesquisas no campo da educação ambiental:

- Qual o foco nas pesquisas sobre percepção ambiental?

Reflexão: os objetos dos estudos sobre percepção ambiental não devem se restringir às formas como os atores sociais vêem os problemas ambientais. As respostas derivadas dessa questão nos trazem formulações conceituais, muitas vezes não derivadas das vivências, das experiências perceptivas, mas de informações descontextualizadas apresentadas pela mídia. Nosso objeto é muito mais as formas com que o ser humano se mistura com o mundo, vivencia suas concretudes, se relaciona com os problemas e, coletivamente, tenta construir uma discursividade autêntica que dê conta de exprimir seus modos de viver. Os estudos sobre percepção deveriam se ocupar, portanto, muito mais que do produto discursivo, que, por vezes, e pela influência de múltiplos fatores (alienação, relações de poder, imaturidade política, indústria cultural, desaprendizagem do senso coletivo, etc.), se apresenta esvaziado de sentidos. Deveriam ir à gênese da existência e descrever os múltiplos modos de vida reveladores do real sentido de inserção do ser humano no seu ambiente. É somente na redescoberta desses modos de viver e de se relacionar com a natureza, o lugar habitado e a coletividade que se pode ancorar uma postura sensível e 
pró-ativa e uma discursividade enraizada, crítica, capaz de gerar o comprometimento das pessoas, focos das metas da educação ambiental.

-Quais abordagens teóricas estão sendo adotadas nos estudos sobre percepção ambiental no campo? Estamos tendo clareza na adoção desses referenciais?

Reflexão: as demandas por pesquisa no campo da educação ambiental se dão, primeiramente, pela necessidade de investigações teóricas, a partir das diferentes áreas de conhecimento que são ou possam vir a ser aportes adequados, como as mencionadas Filosofia, Psicologia, Geografia e Arquitetura, na tentativa de superar as fragilidades teórico-metodológicas e possíveis confusões conceituais. O significado dos estudos empíricos de percepção junto às diferentes comunidades depende da clara definição desses eixos teóricos. É preciso, ainda, atentar para a adoção adequada do fenômeno quando se apresentam essas propostas de investigação empírica, evitando a falta de pertinência dos objetivos e dos procedimentos metodológicos aos seus pressupostos.

-Qual a relevância científica e social dos estudos que vêm sendo desenvolvidos?

Reflexão: é preciso que nos perguntemos até que ponto nossas questões de pesquisa são, de fato, instigadas por uma inquietação real, associada às necessidades de incremento teórico do campo ou de busca de subsídios para as ações de gestão da educação ambiental.

\section{Demandas e perspectivas dos estudos no campo.}

A partir de atividades desenvolvidas durante o IV Encontro de Pesquisa em Educação Ambiental, realizado entre 15 e 18 de julho de 2007, no Grupo de Discussão de Pesquisa em Educação Ambiental e Percepção Ambiental, foi possível colocar essas considerações prévias em discussão e levantar as principais dificuldades nos trabalhos no campo e sugestões de ações futuras. 
Dessa discussão participaram profissionais de diferentes áreas que lidam direta ou indiretamente com estudos sobre percepção ambiental, a saber: Biologia, Geociências, Geografia, Educação, Ecologia, Química, Direito, Jornalismo, Ciências Sociais e Filosofia. Vale ressaltar que esses participantes representavam diversas instituições de ensino superior das várias regiões do país (UENP, UEPG, UFMS, UFMT, UFT, UNEMAT, UNESP, UNICAMP, UFSCar, USP, ESALQ/USP), além de ONGs, órgãos públicos de gestão (CEMASI , SEMASA) e empresas de consultoria ambiental. Os trabalhos desenvolvidos pelo grupo, incluindo projetos, têm o seguinte perfil: com relação ao público atingido, destacam-se comunidades, escolas, crianças e jovens, unidades de conservação, ONGs e projeto socioambiental com jovens de baixa renda. O foco temático desses trabalhos é também diverso: construção social da imagem; representação; significados do contato com a natureza; percepção ambiental na formação e atividades em trilhas.

O grupo concorda com a idéia previamente apresentada pelo texto gerador, segundo a qual:

- há uma determinada complexidade na natureza do fenômeno, o que gera uma demanda por aportes teóricos de outras áreas do conhecimento;

- essa complexidade se revela no surgimento de vários conceitos articuladores quando se busca evidenciar como se dá a percepção, tais como memória, imaginário e construção social da imagem, conhecimentos populares, elementos estéticos, processos cognitivos e topofilia;

- há uma certa superficialidade, detectável nos estudos no campo da educação ambiental, no uso desses conceitos e seus fundamentos advindos de outras áreas de conhecimento;

- o não-entendimento do real sentido do fenômeno tem significado alguns reducionismos nos estudos da percepção no campo da educação ambiental, especialmente nos que se caracterizam pela reprodução de levantamentos conceituais e pela falta de fundamentação teórica adequada. 
Diante dessas reflexões, considerou-se que é necessária uma definição de percepção ambiental no campo, mas que essa busca precisa ser feita com parcimônia, de forma a não significar um enquadramento num conceito que deixe de abrigar a sua natureza complexa e transdisciplinar. Nesse sentido, deve-se evitar tender para um quadro homogêneo, respeitando assim as ramificações necessárias conforme a abordagem teórica adotada, que pode derivar de focos temáticos diversos, dos quais se destacaram alguns exemplos baseados em experiências de estudos nos campos da Geografia Humanística (estudos das bases topofilicas da percepção), da Educação (aspectos cognitivos e sócio-históricos), da Psicologia (experiências significativas de vida e memória), da Sociologia, (questões sobre imaginário e sobre construção social da interação ser humano-ambiente) e da Filosofia (as bases fenomenológicas da percepção e suas dimensões ética e estética).

Derivada das considerações sobre coerência temática e de abordagem teórica, a importância da adequação metodológica também foi destacada pelo grupo, indicando as metodologias focadas no caráter interpretativo dos fatos como as mais viáveis aos estudos no campo.

Outra preocupação levantada está centrada igualmente nessa complexidade do fenômeno que acaba por abrigar essa referida diversidade de categorias envolvidas na sua elucidação: se o caminho para o melhor esclarecimento da percepção é a execução de estudos parciais envolvendo cada um desses conceitos ou categorias ou se será mais producente a tentativa de estudos que os tratem de forma integrada. A idéia mais sintética dessa discussão, que espelha a principal perspectiva vislumbrada pelo grupo para o campo, é o reconhecimento de que haverá um período de identificação em que possivelmente surgirão estudos parciais, enfocando um ou outro aspecto do fenômeno, mas há que se buscar sempre a meta de atender às suas três dimensões essenciais: psicoafetiva, cultural e social.

O desafio de lidar com este momento de buscas de elucidações no campo motivou o interesse do grupo em se configurar como grupo de trabalho, que terá por primeira meta o mapeamento dos estudos sobre percepção ambiental no campo, de forma a conseguir disponibilizar sinalizadores para a evolução desses estudos. Os objetivos principais são: 
avançar na compreensão da natureza do fenômeno; cuidar para não desenvolver estudos a campo sem ter estruturadas definições claras e bem fundamentadas; enfrentar o necessário diálogo de saberes exigido pelos estudos com percepção; buscar a aproximação com grupos de pesquisa que têm desenvolvido trabalhos com percepção ambiental.

\section{Referências}

ALVES-MAZOTTI, Alda J. Relevância e aplicabilidade da pesquisa em educação. Cadernos de Pesquisa, São Paulo, n. 113, p. 39-50, jul. 2001.

ANDRÉ, Marli. Pesquisa em educação: buscando rigor e qualidade. Cadernos de Pesquisa, São Paulo, n. 113, p. 51-64, jul. 2001.

ARANTES, Otília B.F. O lugar da arquitetura depois dos modernos. São Paulo: Edusp, 1993.

BACHELARD, Gaston. A Poética do Espaço. Trad. de Antônio de Pádua Danesi. São Paulo: Martins Fontes, 1993.

BLEY, Lineu. Percepção do espaço urbano: o centro de Curitiba. Dissertação (Mestrado) Instituto de Geociências, Universidade Estadual Paulista, Rio Claro, 1982.

CARMO, Paulo S. Merleau-Ponty: uma introdução. São Paulo: Educ, 2000.

CASSIRER, Ernst. A filosofia das formas simbólicas. Trad. de Marion Fleischer. São Paulo: Martins Fontes, 2001.

DANIEL, Michelle H. Referenciais teórico-metodológicos nas pesquisas em educaşão ambiental no ambiente escolar. 2006. 55 f. Monografia (Trabalho de Conclusão de Curso) - Universidade Federal do Paraná, Curitiba, 2006.

DEL RIO, Vicente; OLIVEIRA, Lívia. Percepção ambiental: a experiência brasileira. 2. ed. São Paulo: Studio Nobel, 1999.

DEL RIO, Vicente; DUARTE, Cristiane R.; RHEINGANTZ, Paulo A. Projeto do lugar: colaboração entre psicologia, arquitetura e urbanismo. Rio de Janeiro: Contra Capa, 2002.

DUARTE Júnior, João Francisco. Fundamentos estéticos da educação. 2aed. Campinas, SP: Papirus, 1988. 150p.

DUARTE Júnior, João Francisco. O sentido dos sentidos: a educação (do) sensível. 3a.ed. Curitiba: Criar Edições, 2004.

DUFRENNE, Mikel. Estética e Filosofia. 3. ed. Trad. de Roberto Figurelli. São Paulo: Perspectiva, 2002.

ELIADE, Mircea. Imagens e símbolos: ensaios sobre o simbolismo mágico-religioso. Trad. de Sandra Cristina Tamer. São Paulo: Martins Fontes, 1991. 
FREITAS, Denise; OLIVEIRA, Haydée T. Pesquisa em educação ambiental: um panorama de suas tendências metodológicas. Pesquisa em Educaşão Ambiental, São Carlos, SP, v. 1, n. 1, p. 175-191, jul./dez. 2006.

FRÓIS, Kátia P. Revisão da percepção da arquitetura em Bruno Zevi, Christian NorbergSchulz e através de Heidegger até a possibilidade fenomenológica de Merleau-Ponty. OLAM Ciência e Tecnologia, Rio Claro, v. 1, n. 2, p. 123-152, nov. 2001.

HEIMSTRA, Norman W.; MacFARLING, Leslie H. Psicologia ambiental. São Paulo: EPU; Edusp, 1978.

HOCHBERG, Julian E. Percepşão. Trad. de Álvaro Cabral. Rio de Janeiro: Zahar, 1973.

HOLZER, W. A geografia humanista: uma revisão. Espaço e cultura, Rio de Janeiro, n. 3, p. 819, 1996.

LEE, Terence. Psicologia e meio ambiente. Trad. de Álvaro Cabral. Rio de Janeiro: Zahar, 1977.

LÓPEZ QUINTÁS, Alfonso. Estética. Trad. de Jaime A. Clasen. Petrópolis: Vozes, 1992.

MAFFESOLI, Michel. No fundo das aparências. Trad. de Bertha Halpern Guravitz. Petrópolis, RJ: Vozes, 1996.

MARIN, Andreia A. Percepção ambiental e imaginário dos moradores do município de Jardins/MS. 2003. 306 f. Tese (Doutorado) - Centro de Ciências Biológicas e da Saúde, Universidade Federal de São Carlos, São Carlos, 2003.

MARIN, Andreia A.; OLIVEIRA, Haydée T.; COMAR, Vito. A educação ambiental num contexto de complexidade do campo teórico da percepção. Interciência, Caracas, v. 28, n. 10, p. 616-619, out. 2003.

MELO, Vera L.M.O. A paisagem sob a perspectiva das novas abordagens geográficas. In: ENCONTRO DE GEÓGRAFOS DA AMÉRICA LATINA, 10., 2005, São Paulo. Anais... São Paulo: Universidade de São Paulo, 2005. p.9146-9165.

MERLEAU-PONTY, M. Fenomenologia da percepção. 2. ed. Trad. de Carlos Alberto Ribeiro de Moura. São Paulo: Martins Fontes, 1999.

OKAMOTO, Jun. Percepção ambiental e comportamento: visão holística da percepção ambiental na arquitetura e na comunicação. São Paulo: Ed. Mackenzie, 2002.

OLIVEIRA, Lívia de. Percepção do meio ambiente e geografia. OLAM Ciência e Tecnologia, Rio Claro, v. 1, n. 2, p. 14-28, nov. 2001.

PACHECO, Éser; SILVA, Hilton P. Compromissos epistemológicos do conceito de percepção ambiental. In: CONGRESSO DE ECOLOGIA DO BRASIL, 7., 2005, Caxambu, MG. Disponível em: <http://www.ivt-j.net/sapis/2006/pdf/EserPacheco.pdf>. Acesso em: 09 jun. 2007.

PINHEIRO, José Queiroz. O lugar e o papel da Psicologia Ambiental no estudo das questões humano-ambientais, segundo grupos de pesquisa brasileiros. Psicologia USP, São Paulo, v. 16, n. 1/2, p. 103-113, 2005.

RELPH, Edward. Place and Placelessness. London: Pion, 1976.

SERPA, Ângelo. Percepção e fenomenologia: em busca de um método humanístico para estudos e intervenções do/no lugar. OLAM Ciência e Tecnologia, Rio Claro, v. 1, n. 2, p. 29-61, nov. 2001. 
SIMÕES, Edda A. Q.; TIEDEMANN, Klaus B. Psicologia da percep̧̧ão I. São Paulo: EPU, 1985.

TUAN, Y. F. Humanistic Geography. Annals of the Association of American Geographers, Washington, v. 66, n. 2, p. 266-276, jun. 1976.

Topofilia. Trad. de Lívia de Oliveira. São Paulo: Difel, 1980.

WHITE, Anne V. T. Guidelines for fields studies in Environmental Perception. Paris: UNESCO/MAB, 1977.

\section{Agradecimentos}

* A todos os participantes do GDP Educação Ambiental e Percepção Ambiental, que demonstraram uma grande maturidade e sensibilidade para o diálogo aberto, sabendo ouvir e corroborar ou contrapor delicada e construtivamente as idéias apresentadas.

+ À prof . Haydée Torres Oliveira, que oportunizou momentos fundamentais de discussão sobre percepção e educação ambiental, orientando nossas investigações sobre o tema.

* Ao prof. Dr. Marcos Reigota, cuja importância na consolidação do campo de pesquisa em educação ambiental no país é indiscutível e que, no início das nossas pesquisas sobre percepção, indicou importantes possibilidades de suporte teórico.

Artigo recebido em 28/08/2007 - Aprovado em 08/06/2008 